\title{
PERILAKU HIDUP BERSIH DAN SEHAT DI KELURAHAN JELEKONG KABUPATEN BANDUNG
}

\section{CLEAN AND HEALTHY LIVING BEHAVIOR IN KELURAHAN JELEKONG, BANDUNG DISTRICT}

\author{
${ }^{1)}$ Diana Krisanti Jasaputra, ${ }^{2)}$ Dani, ${ }^{3)}$ Felisia Hilianti \\ ${ }^{1,2,3)}$ Program Studi Pendidikan Dokter, Fakultas Kedokteran \\ Universitas Kristen Maranatha \\ J1 Surya Sumantri no 65 Bandung \\ *Email: dianakjasaputra14@gmail.com
}

\begin{abstract}
ABSTRAK
Semua penduduk kampung dalam menjaga kesehatan perlu menjaga perilaku hidup bersih dan sehat (PHBS) termasuk di Kelurahan Jelekong, Bandung. Salah satu kegiatan Gerakan Masyarakat Hidup Sehat (GERMAS) adalah PHBS. Tujuan kegiatan pengabdian ini adalah memberi penyuluhan mengenai PHBS agar dapat mencegah penyakit tidak menular. Pelaksanaan pengabdian kepada masyarakat dilakukan dengan penyuluhan mengenai PHBS. Penyuluhan PHBS meliputi cara-cara mencuci tangan, saat sebelum dan sesudah makan, sebelum mempersiapkan makanan, setelah $B A B / B A K$. Penyuluhan yang dilakukan adalah mengenai pentingnya penggunaan jamban, dan memiliki jamban pribadi. Penyuluhan juga menekankan pentingnya makan makanan sehat yaitu buah dan sayur setiap hari, demikian juga melakukan olah raga seperti berjalan kaki 2-3 kali seminggu. Topik penyuluhan berikutnya adalah pentingnya memberantas jentik-jentik nyamuk dengan 3M. Masyarakat yang mengikuti penyuluhan kemudian diminta untuk mengisi survei sehingga akan diperoleh data awal untuk tindak lanjut berikutnya guna mencegah penyakit tidak menular.
\end{abstract}

Kata kunci: Jelekong; GERMAS; PHBS

\section{ABSTRACT}

In maintaining health conditions, all villagers need to maintain a clean and healthy lifestyle (PHBS), including in Jelekong Village, Bandung. PHBS is part of the Healthy Living Community Movement (GERMAS). The objective of this community service is to provide counseling about PHBS in order to prevent non-communicable diseases. Community service delivery by counseling about PHBS. PHBS counseling includes ways to wash hands, before and after eating, before preparing food, after defecation. The counseling was about the importance of using a toilet and having a private toilet. The counseling also emphasizes the importance of eating vegetables and fruit daily and carrying out physical activities such as walking 2-3 times a week. The next counseling topic is the importance of eradicating mosquito larvae with $3 \mathrm{M}$. The community that follows the counseling then be asked to fill out a survey so that initial data will be obtained for further follow-up to prevent non-communicable diseases.

Keywords: Jelekong; GERMAS; PHBS

Submitted : 22 November 2019 Revision : 28 Juli 2020 Accepted : 6 September 2020 


\section{PENDAHULUAN}

Kegiatan Tridarma Perguruan tinggi termasuk pengabdian kepada masyarakat wajib dilaksanakan. Pelaksanaan pengabdian masyarakat program studi pendidikan dokter Faklutas Kedokteran Universitas Kristen Maranatha dalam rangka kegiatan Kuliah Kerja Nyata (KKN) Tematik Citarum Harum memilih tempat keluran Jelekong, Kabupaten Bandung. Kelurahan Jelekong termasuk Kecamatan Baleendah Kabupaten Bandung, terletak di Jl. Laswi Cangkring No.230, Jelekong, Baleendah, Bandung, Jawa Barat

Kampung Jelekong adalah kampung wisata, yang menyajikan berbagai lukisan. Kampung Wisata Jelekong menyajikan berbagai lukisan indah yang berderet-deret di kios-kios kelurahan Jelekong. Mayoritas penduduk kampung Jelekong adalah pelukis. Harga lukisan dari berkisar dari ratusan ribu sampai hingga jutaan rupiah.

Perilaku hidup bersih dan sehat (PHBS) perlu dilakukan oleh semua penduduk kampung untuk menjaga kesehatan. PHBS merupakan bagian dari Gerakan Masyarakat Hidup Sehat (GERMAS). Pola penyakit terkait dengan perilaku manusia dalam 30 tahun terakhir mengalami perubahan dari penyakit menular seperti infeksi saluran napas, ke penyakit tidak menular, seperti stroke, tekanan darah tinggi, penyakit jantung koroner, kencing manis, dan kanker. Faktor risiko penyakit tidak menular antara lain kurangnya aktivitas fisik, kurangnya konsumsi makanan sehat, seperti buah dan sayur, merokok, minum alkohol. Penyakitpenyakit tersebut dicegah dengan Gerakan Masyarakat Hidup Sehat (GERMAS). GERMAS yang dilakukan oleh seluruh komponen bangsa secara sadar dan merupakan suatu tindakan sistematik dan terencana yang dilakukan secara bersamasama dengan dasar kemauan dan kemampuan berperilaku sehat untuk meningkatkan kualitas hidup. Ruang lingkup gerakan masyarakat hidup sehat meliputi peningkatan kualitas lingkungan, peningkatan edukasi hidup sehat, peningkatan pencegahan dan deteksi dari penyakit, percepatan perbaikan gizi, penyediaan pangan sehat dan peningkatan perilaku hidup sehat, serta peningkatan olah raga. Sepuluh pesan untuk mencapai rumah tangga ber-PHBS, yaitu (1) persalinan ditolong oleh tenaga kesehatan, (2) menimbang balita setiap bulan, (3) memberi ASI eksklusif (4) mencuci tangan dengan air bersih dan sabun, (5) menggunakan air bersih, (6) menggunakan jamban sehat, (7) makan buah dan sayur setiap hari, (8) memberantas jentik di rumah sekali seminggu, (9) tidak merokok di dalam rumah, dan (10) melakukan aktivitas fisik setiap hari (Kemenkes RI, 2016).

Sosialisasi dan pelaksanaan gerakan masyarakat hidup sehat (GERMAS) telah diinisiasi dan dilakukan di semua tempat di Indonesia, termasuk di Poltekes Kemenkes Palu. Kegiatan yang dilakukan di tempat ini melibatkan seluruh pegawai Poltekes Kemenkes Palu berjumlah 167 orang yang disurvei mengenai asupan buah dan aktivitas fisik responden. Hasil surveinya menunjukkan bahwa asupan buah dan aktivitas fisik reseponden baik, yang berdampak pada baiknya tekanan darah dan kadar glukosa darah responden (Zainul, et al., 2019).

Hidup sehat melalui GERMAS juga dibudayakan di Dusun Mendang III, Jambu dan Jrakah, Kecamatan Tanjungsari, Gunungkidul. Kegiatan ini memberikan hasil bertambahnya pengetahuan tentang pentingnya menjaga kesehatan melalui GERMAS, meningkatnya kesadaran dan PHBS, dan masyarakat menerapkan langsung PHBS dalam kehidupan seharihari (Suryani, et al., 2018). Sosialisasi program GERMAS juga telah dilakukan di wilayah kerja Puskesmas Kecamatan Sukarame Palembang, yang ternyata berhubungan dengan kebiasaan hidup masyarakat yang baik (Tedi, Fadly, \& Ridho, 2018). 
Pencegahan penyakit tidak menular harus melibatkan masyarakat. Peningkatan peran serta masyarakat diharapkan dapat menurunkan angka penyakit tidak menular (Nopriyanto, et al., 2019).

Berdasarkan latar belakang tersebut, pencegahan penyakit tidak menular harus melibatkan masyarakat untuk efektivitas keberhasilan program. Kegiatan pengabdian kepada masyarakat di Kelurahan Jelekong ini berupa penyuluhan mengenai pola hidup sehat dan bersih., yang dinilai keberhasilannya menggunkan survey dan dengan tujuan akhir mencegah penyakit tidak menular.

\section{METODE}

Kegiatan pengabdian kepada masyarakat ini menggunakan metode penyuluhan pada Keluran Jelekong yang dilaksankan oleh mahasiswa mengenai gerakan masyarakat hidup sehat (GERMAS), yaitu perilaku hidup sehat dan bersih

Pelaksanaan kegiatan pengabdian kepada masyarakat di kelurahan Jelekong diawali dengan penyuluhan mengenai PHBS mengenai 6 hal yaitu (1) menggunakan jamban sehat, menggunakan air bersih (3), mencuci tangan dengan air bersih dan sabun, (4) makan buah dan sayur setiap hari, , (5) memberantas jentik di rumah sekali seminggu (6) melakukan aktivitas fisik setiap hari.

\section{HASIL DAN PEMBAHASAN}

Kegiatan pengabdian kepada masyarakat di Kelurahan Jelekong ini berupa penyuluhan mengenai PHBS. Pelaksanaan kegiatan diawali dengan sambutan dari pihak Kelurahan Jelekong dan dari pihak Universitas Kristen Maranatha (gambar 1).

Pelaksanaan penyuluhan (gambar 2 dan 3) meliputi definisi PHBS, yaitu perilaku yang dapat menjadikan keluarga, kelompok atau masyarakat mampu hidup mandiri dalam hal menjaga kesehatan dan berperan aktif dalam mewujudkan kesehatan seluruh masyarakat.

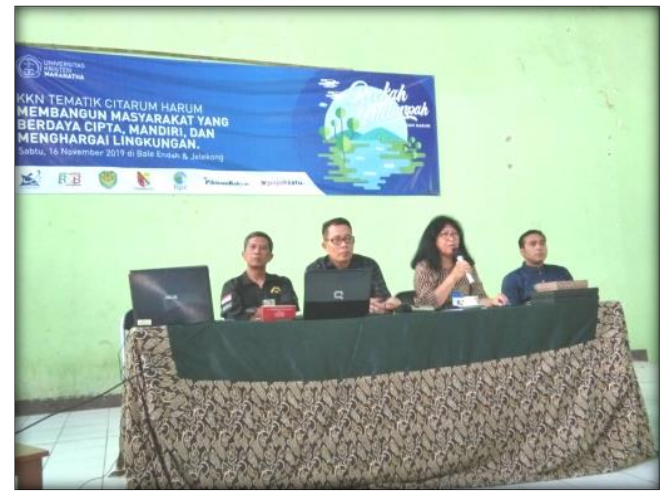

Gambar 1. Pembukaan Kegiatan

Pengabdian kepada

Masyarakat di Kelurahan Jelekong

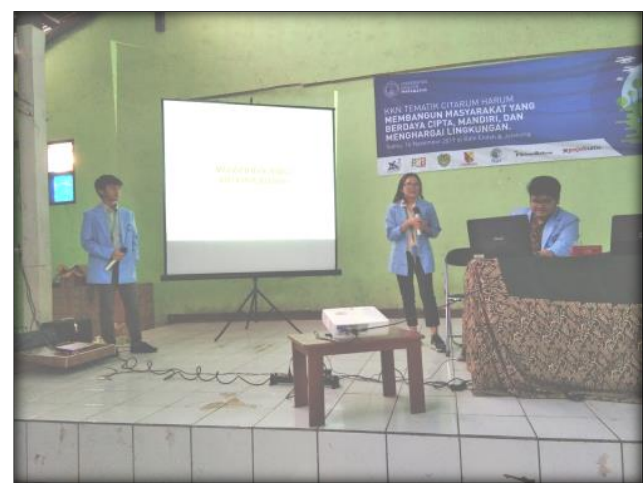

Gambar 2. Penyuluhan PHBS oleh mahasiswa di Kelurahan Jelekong

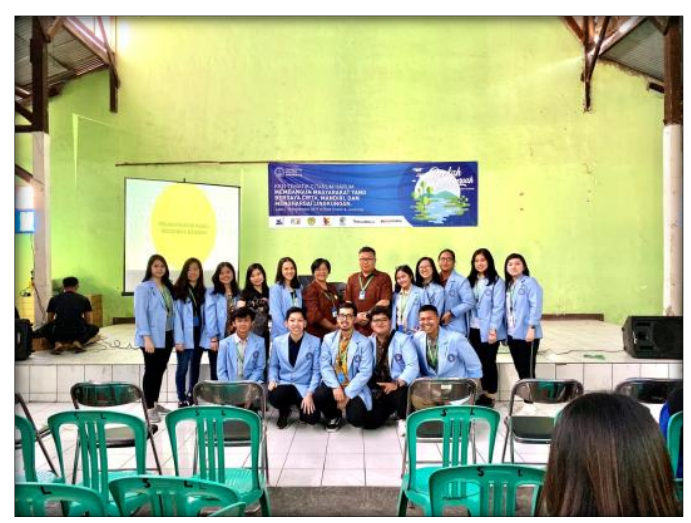

Gambar 3. Dokumentasi kegiatan pengabdian kepada masyarakat di Kelurahan Jelengkong 


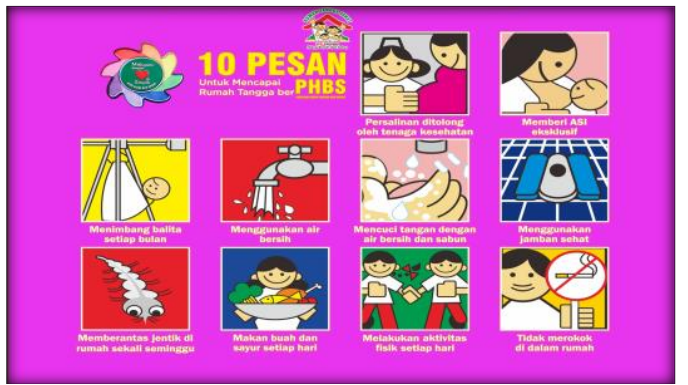

Gambar 4. 10 pesan untuk mencapat rumah tangga ber PHBS

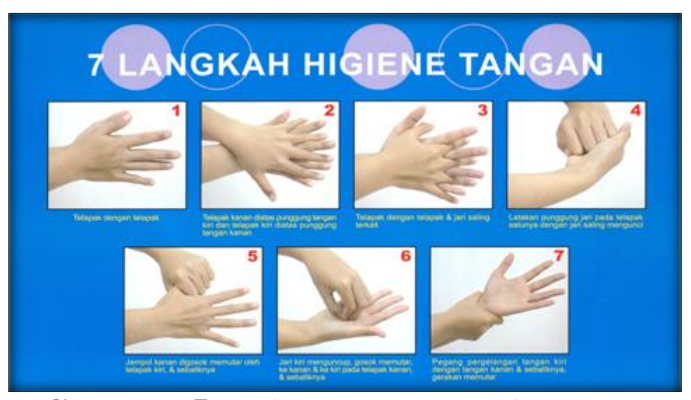

Gambar 5. Tujuh langkah cuci tangan

$$
\text { Penyuluhan PHBS juga }
$$

menekankan pada 7 langkah mencuci tangan yang dianjurkan. (Gambar 5). Penyuluhan kepada masyarakat menganjurkan untuk penggunaan air bersih secara bijaksana, yaitu menjaga sumber mata air dari pencemaran. Penggunaan air bersih bermanfaat mencegah diare, tifus abdominalis, disentri, kolera, penyakit mata dan lain-lain. Kebersihan air harus tetap dijaga, tidak ada genangan air di sekitar sumber air, dan harus ada saluran pembuangan air, bebas kotoran, bebas lumut, baik lantai, maupun dinding sumur. Jarak sumber air dan jamban serta tempat pembuangan sampah minimal 10 meter.

Sumur gali, sumur pompa, keran umum, dan mata air harus dijaga agar tidak rusak, dan lain sebagainya. Lantai sumur harus kedap air (diplester) dan tidak ada yang retak, bibir sumur dan dinding sumur wajib diplester dan sumur harus ditutup. Ember penampungan air harus lengkap dengan penutup dan gayung bertangkai, yang bersih.
PHBS meliputi juga penggunaan jamban sehat dengan kriteria : tidak mencemari air, jarak septic tank dan sumur minimal 10 meter, kotoran tidak dibuang ke selokan, empang, danau, sungai dan laut. Tanah permukaan tidak boleh tercemari kotoran dari jamban. Jamban juga harus bebas serangga, wangi, dan nyaman digunakan, aman bagi penggunanya, kebersihannya terjaga, dan pemandangannya harus dijaga kesopannnya, artinya jamban harus berdinding dan berpintu.

PHBS juga harus dilaksanakan dengan memberantas jentik-jentik nyamuk dengan gerakan $3 \mathrm{M}$ yaitu menguras, menutup, dan mengubur. Perilaku hidup sehat juga meliputi konsumsi sayursayuran dan buah-buahan, dan tidak lupa melakukan aktivitas fisik / berolah raga 3-5 kali seminggu. Penyakit tidak menular juga dilakukan dengan melakukan aktivitas fisik. Beberapa manfaat aktivitas fisik antara lain mengurangi risiko kematian dini, meningkatkan kerja otot jantung paru, mengendalikan stress, mengurangi kecemasan dan depresi, meningkatkan keseimbangan, mengoptimalkan tumbuh kembang, meningkatkan metabolisme tubuh, , mengurangi risiko penyakit kanker usus besar, meningkatkan fleksibilitas, memelihara tulang, otot, dan sendi yang sehat, mengurangi risiko tekanan darah tinggi, mengurangi risiko diabetes, mengendalikan berat badan, mencegah penyekit tidak menular, meningkatkan kerja/mengurangi risiko penyakit jantung, dan meningkatkan kemampuan dan keterampilan tubuh (Kemenkes RI, 2016).

Kegiatan pengabdian kepada masyarakat serupa antara lain gerakan masyarakat (GERMAS) mencuci tangan menggunakan sabun dan air mengalir sebagai upaya untuk menerapkan perilaku hidup bersih dan sehat (PHBS) sejak dini dan hasilnya terdapat peningkatan pengetahuan orang tua murid Pendidikan Anak Usia Dini (PAUD) setelah 
penyuluhan PHBS (Ambarwati \& Prihastuti, 2019)

Kegiatan pengabdian kepada masyarakat lain yang telah dilaksanakan dengan topik PHBS, yaitu Perilaku hidup bersih dan sehat (PHBS) pada tatanan rumah tangga masyarakat Using, dengan hasil yang menunjukkan bahwa masyarakat menggunakan air bersih yang bersumber dari mata air pegunungan dan masyarakat Using masih buang air besar di sungai, pemilahan sampah masih belum menjadi kebiasaan dan sering membuang sampah di pinggir sungai. Walaupun kepala desa sudah mewajibkan setiap rumah harus memiliki jamban supaya terdapat pengurang kebiasaan masyarakat buang air besardi sungai. Tim penggerak PKK termasuk ibu kepala desa sudah melakukan penyuluhan mengenai daur ulang sampah namun responnya belum sesuai harapan (Gani, Istiaji, \& Pratiwi, 2015)

Kegiatan pengabdian kepada masyarakat dengan judul Perilaku hidup bersih dan sehat (PHBS) pada tatanan rumah tangga masyarakat desa Parang Badodo, memberikan hasil pencapaian masyarakat yang melaksanakan PHBS di dusun Parang Baddo sebesar 63,2\% sedangkan di Parang Bianara 58,65\%. Target PHBS yang dibuat oleh Kementerian Kesehatan adalah $70 \%$, sedangkan hasil pencapaian di kedua dusun tersebut masih di bawah target. Dengan demikian, pencapaian PHBS masih dibawah standar target Kementerian Kesehatan di masyarakat desa Parang Baddo khususnya dusun Parang Baddo dan Parang Bianara. Petugas kesehatan disarankan untuk mengaktifkan kader kesehatan di desa Parang Baddo, yang memberikan penyuluhan sekaligus melakukan pendampingan pada perkembangan PHBS di desa Parang Baddo (Natsir, 2019)

Hasil kegiatan pengabdian kepada masyarakat di Kota Bandung, menunjukkan bahwa di wilayah Bandung
Barat, kejadian diare ada hubungannya dengan perilaku hidup bersih dan sehat. Angka bebas larva dalam rumah tangga berbanding lurus denga penurunan kasus Demam Berdarah. Penyakit diare, dan demam berdarah serta angka bebas larva berhubungan langsung dengan Perilaku Hidup Bersih dan Sehat. Hasil studi ini diharapkan digunakan oleh pembuat kebijakan kesehatan yang memprirotaskan PHBS harus menjadi program utama untuk pengendalian penyakit menular dan mitigasi dampak perubahan iklim terhadap esehatan masyarakat (Raksanagara \& Raksanagara, 2015)

Perilaku hidup bersih dan sehat sangat penting untuk diketahui dan dilakukan dalam kehidupan sehari-hari, baik bagi masyarakat di desa maupun masyarakat kota. Sebagaimana telah dilakukan dalam kegiatan pengabdian kepada masyarakat berupa penyuluhan PHBS dalam kehidupan sehari-hari sekaligus memberikan pengetahuan bagamana cara merealisasikannya sehingga dapat terwujud masyarakat yang peduli sehat (Andriansyah \& Rahmatari, 2013).

Upaya mensosialisasikan perilaku hidup bersih dan sehat melalui berbagai kegiatan pengabdian kepada masyarakat telah banyak dilakukan untuk mendukung gerakan masyarakat hidup sehat dengan tujuan akhir mengurangi penyakit tidak menular yang akhir-akhir ini meningkat. Kegiatan pengabdian kepada masyarakat tersebur termasuk yang dilakukan pada KKN Tematik Citarum Harum oleh mahasiswa Fakultas Kedokteran Universitas Kristen Maranatha di Kelurahan Jelekong, Kabupaten Bandung, pada tanggal 16 November 2019. Kegiatan pengabdian masyarakat ini merupakan bentuk pelaksanaan tridarma perguruan tinggi, dan juga merupakan bentuk pengejawantahan core value yang di bangun di Universitas Kristen Maranatha. Core value yang dimaksud di sini adalah nilai kepedulian, yaitu kepedulian kepada kesehatan masyarakat. Harapan kegiatan 
ini adalah terwujudnya kesehatan masyarakat yang terus mengalami peningkatan.

\section{SIMPULAN}

Kegiatan pengabdian kepada masyarakat di Kelurahan Jelekong mengenai PHBS telah dilaksanakan dengan baik. Kegiatan pengbdian kepada masyarakat ini tidak hanya bermanfaat bagi masyarakat yang langsung mengikutinya, namun, lebih jauh dari itu, diharapkan dapat ikut berperan untuk mendorong seluruh masyarakat Indonesia mamahami dan melaksanakan PHBS dalam kehidupannya sehari-hari, dengan hasil akhir angka kesakitan dan angka kematian menurun.

\section{UCAPAN TERIMA KASIH}

Ucapan terima kasih diberikan kepada penyandang dana KKN Tematik Citarum Harum, yaitu Kemenristekdikti Dirjen Pembelajaran dan Kemahasiswaan RI.

Ucapan terima kasih diberikan juga kepada Bapak Lurah Jelekong, beserta seluruh aparatnya, Wakil Rektor I UKM, Ibu Olga Catherina Pattipawaej, PhD. Ketua LPPM UKM, Dr. Teresa Liliana Wargaseria, S.Si., M. Kes., PA (K)., yang telah memfasilitasi sehingga kegiatan ini dapat berlangsung. Ucapan terima kasih juga diberikan kepada July Ivone., dr., MKK., MPd. Ked. dalam pembuatan kuesioner untuk survei menganai PHBS. Terima kasih untuk adik-adik mahasiswa yang teribat dalam kegiatan ini yaitu Reynaldi Sugianto, Erica Valencia Imannuel, Gede Anggara Setya Dewa Brata, Octaviena Zakaria, Sheilla Meriyani, Stefanie Sumartono, Sartika Natalia Sihasale, Devina Gloria, Kheren Pricilia, Novie Kartika, Farrel Dinda Athallah Siregar, Fiorentini Rachma Diandi, Sultas Fauzan Alfikri, Jerrick Lo Abednego.

\section{DAFTAR PUSTAKA}

Ambarwati, E.R. \& Prihastuti. (2019) Gerakan masyarakat (GERMAS) mencuci tangan menggunakan sabun dan air mengalir sebagai upaya untuk menerapkan perilaku hidup bersih dan sehat (PHBS) sejak dini. Celebes Abdimas : Jurnal Pengabdian Kepada Masyarakat, 1 (1): 45-52.

Andriansyah, Y. \& Rahmatari, D.N. (2013). Penyuluhan dan praktik PHBS (Perilaku Hidup Bersih Sehat) dalam mewujudkan masyarakat desa peduli. Jurnal Inovasi dan Kewirausahaan. 2(1): 45-50.

Gani, H.A., Istiaji, E., Pratiwi, P.E. (2015). Perilaku hidup bersih dan sehat (PHBS) pada tatanan rumah tangga masyarakat Using (Studi Kualitatif di Desa Kemiren, Kecamatan Glagah, Kabupaten Banyuwangi), Jurnal IKESMA 11(1) : 25-35. Retrieved from https://jurnal.unej.ac.id/index.php/I KESMA/article/view/4347

Kemenkes RI (2016). Buku Panduan GERMAS Gerakan Masyarakat Hidup Sehat. http://promkes.kemkes.go.id.

Natsir, M.F. (2019). Perilaku hidup bersih dan sehat (PHBS) pada tatanan rumah tangga masyarakat desa Parang Badodo. Jurnal Nasional Ilmu Kesehatan (JNIK), 1(3) : 54-59.

Nopriyanto, D., Aminuddin, M., Samsugito, I., Puspasari, R. Ruminem, R., \& Syukmana., M. (2019), Meningkatkan Peran Serta Masyarakar Dalam Upaya Menurunkan Peningkatan Penyakit Tidak Menular (PTM), JPPM (Jurnal Pengabdian dan Pemberdayaan Masyarakat), 3(2): 285-292. http://dx.doi.org/10.30595/jppm.v3i $\underline{2.4726}$ 
Raksanagara, A. \& Raksanagara, A. (2015) Perilaku hidup bersih dan sehat sebagai determinan kesehatan yang penting pada tatanan rumah tangga di Kota Bandung. JSK. Jurnal Sistem Kesehatan, 1(1) : 30-34. https://doi.org/10.24198/jsk.v1i1.10 $\underline{340}$

Suryani, D. Nurdjanah, E.P., Yogatama, Y., Jumadil, M. (2018). Membudayakan Hidup Sehat Melalui Gerakan Masyarakat Hidup Sehat (GERMAS) di Dusun Mendang III, Jambu dan Jrakah Kecamatan Tanjungsari, Gunung Kidul. Jurnal Pemberdayaan: Publikasi Hasil Pengabdian kepada Masyarakat, 2(1) : 65-74. https://doi.org/10.12928/jp.v2i1.486.

Tedi, T., Fadly, F., Ridho, R. (2018) Hubungan program GERMAS terhadap kebiasaan hidup masyarakat yang telah dan belum mendapatkan sosialisasi di wilayah kerja puskesmas Kecamatan Sukarame Palembang. JPP (Jurnal Kesehatan Poltekkes Palembang). 13(1) : 54-60. https://doi.org/10.36086/jpp.v13i1.7 7 .

Zainul, Junaidi, Nasrul, \& Masudin. (2019) Inisiasi Gerakan Masyarakat Sehat (GERMAS) di Poltekkes Kemenkes Palu. Poltekita: Jurnal Ilmu Kesehatan 13(1) : 54-61. https://doi.org/10.33860/jik.v13i1.33 